\title{
LA PESTE Y EL ARTE, ALGUNAS REFLEXIONES
}

\author{
A PESTE E A ARTE. ALGUMAS REFLEXÕES
}

Celina A. Lértora Mendoza*

\begin{abstract}
O:
La peste es una realidad recurrente en la historia humana desde los más remotos tiempos. Cualquier persona medianamente culta o memoriosa puede mencionar diversas lecturas sobre ella; quien haya vivido más de cinco décadas puede recordar episodios que le tocó presenciar. Así, podemos evocar desde la primera gran peste de que se tengan noticias y narraciones, como la de Atenas en el siglo V ac, hasta la que estamos padeciendo en todo el planeta. La peste ha sido omnipresente en un sentido recurrente en el tiempo y expansivo en el espacio; hoy es omnipresente en sentido absoluto. Además, es un fenómeno impactante, trágico en sí mismo y en sus consecuencias. Provoca grandes sufrimientos físicos en las víctimas, daños psíquicos en todos los directa o indirectamente afectados (miedo, ansiedad, depresión) y consecuencias de enorme significación en la sociedad y en todos los aspectos de la vida, que incluyen a varias generaciones. En este breve trabajo me propongo reflexionar sobre este punto, sin pretender ni mucho menos una historia del tema. Tomaré solamente tres casos que, en cierto modo pueden considerarse ejemplos claros de esta asimetría en que los rasgos negativos prevalecen ampliamente sobre los positivos pero, paradojalmente, sirven de gran marco para destacar los heroísmos y los martirios minoritarios.
\end{abstract}

PALABRAS CLAVE: Peste. Peste negra. Arte. Edad Media.

RESUMO:

A peste é uma realidade recorrente na história da humanidade desde os tempos mais remotos. Qualquer pessoa de cultura moderada ou memorável pode mencionar várias leituras sobre ela; Qualquer pessoa que viveu por mais de cinco décadas pode se lembrar de ter presenciado tais episódios. Assim, podemos evocar desde a primeira grande peste mediante mitos e contos, como a de Atenas do século $\mathrm{V}$ aC, até aquela que estamos sofrendo em todo o planeta. A peste tem sido onipresente em um sentido recorrente no tempo e expansiva no espaço; hoje é onipresente em sentido absoluto. Além disso, é um fenômeno chocante, trágico em si mesmo e em suas consequências. Causa grande sofrimento físico nas vítimas, danos psicológicos em todos os afetados direta ou indiretamente (medo, ansiedade, depressão) e consequências de enorme significado na sociedade e em todos os aspectos da vida, que incluem várias gerações. Neste breve trabalho, proponho refletir sobre este assunto, sem pretender desenvolver uma história sobre o tema. Tomarei apenas três casos que, de certa forma, podem ser considerados exemplos claros dessa assimetria em que os traços negativos predominam em grande parte sobre os positivos, mas, paradoxalmente, servem como um grande quadro para destacar o heroísmo minoritário e o martírio.

PALAVRAS-CHAVE: Peste. Peste Negra. Arte. Idade Média.

\footnotetext{
* Professora na Universidade Católica Argentina, Universidade Nacional de Buenos Aires e Universidade Nacional de Mar del Plata. Curriculum Vitae disponível em: https://ri.conicet.gov.ar/author/5074. E. mail: clertoramendoza@gmail.com.
} 


\section{INTRODUCCIÓN}

La peste es una realidad recurrente en la historia humana desde los más remotos tiempos. Cualquier persona medianamente culta o memoriosa puede mencionar diversas lecturas sobre ella; quien haya vivido más de cinco décadas puede recordar episodios que le tocó presenciar. Así, podemos evocar desde la primera gran peste de que se tengan noticias y narraciones, como la de Atenas en el siglo $\mathrm{V}$ ac, hasta la que estamos padeciendo en todo el planeta. La peste ha sido omnipresente en un sentido recurrente en el tiempo y expansivo en el espacio; hoy es omnipresente en sentido absoluto. Además, es un fenómeno impactante, trágico en sí mismo y en sus consecuencias. Provoca grandes sufrimientos físicos en las víctimas, daños psíquicos en todos los directa o indirectamente afectados (miedo, ansiedad, depresión) y consecuencias de enorme significación en la sociedad y en todos los aspectos de la vida, que incluyen a varias generaciones. Por ejemplo, la peste negra que asoló Europa en el siglo XIV produjo una gran despoblación (perdió un tercio de sus habitantes y recién en el siglo XVII volvió a alcanzar la cantidad de habitantes pre-peste). Una epidemia es ocasión de mostrar el lado más negativo de los seres humanos (egoísmo, aprovechamiento, rapiña, abandono) pero también el lado más positivo (actos heroicos de cuidado aun a costa de la propia salud y la vida). No es de extrañar, por tanto, que haya sido y sea aún un tema de gran interés para los artistas de todos o casi todos los géneros ${ }^{1}$. Sin embargo, una rápida compulsa a ese ingente material muestra una considerable asimetría de tratamiento. Mientras que los aspectos más negativos, dramáticos y repulsivos son elegidos por los artistas (especialmente los plásticos, pero también los literatos) los aspectos positivos suelen quedar reducidos a las narraciones puntuales de algunos héroes y mártires. Muchas veces, incluso, en el marco del horror (narrado o pintado) de la epidemia y del aspecto de los apestados.

En este breve trabajo me propongo reflexionar sobre este punto, sin pretender ni mucho menos una historia del tema. Tomaré solamente tres casos que, en cierto modo pueden considerarse ejemplos claros de esta asimetría en que los rasgos negativos prevalecen ampliamente sobre los positivos pero, paradojalmente, sirven de gran marco para destacar los heroísmos y los martirios minoritarios.

\footnotetext{
${ }^{1}$ La relación entre la enfermedad (en una variedad que incluye la peste) y la muerte es uno de los hechos más antiguos de la humanidad, que se remonta a los tiempos de la última glaciación. Puede conjeturarse que esas primeras pinturas representativas de dicha relación tuvieron un origen religioso, o tal vez simplemente documental. En todo caso han sido una constante cuyo hilo conductor es parte del trabajo de los historiadores. Cf. TOPOLANSKY, Ricardo, El arte y la medicina, Montevideo, 2004-2005, Introducción.
} 


\section{LA PESTE NEGRA DEL SIGLO XIV EN EUROPA}

Es posiblemente el episodio pandémico más visualizado en la historia (general, social, cultural, científica) y en el arte. Es también posiblemente la pandemia mejor estudiada. Precisamente estas investigaciones históricas nos permiten acceder con razonable verosimilitud al sentir de aquellas gentes, y explicarnos así los trazos literarios y plásticos que la evocan y representan.

En el amplio marco de estas historias sectoriales, me detengo solamente en dos ejes. El primero, el enfoque médico, es decir, de qué modo la medicina de la época se enfrentó con la peste $^{2}$. En segundo lugar, el enfoque espiritual-religioso: de qué modo y con qué recursos se explicó, se justificó y se valoró la peste como un momento de crisis y discernimiento. Estos dos aspectos son, a su vez, los destacados por el arte. Es decir, que el arte, de hecho, se apropió con sus recursos de un imaginario social (científico y/o vulgar) y religioso y le dio formas que cuestionan, explícita y frontalmente, la idea de "arte bello" prevalente entre los teóricos de la época. En otras palabras, quiero postular la hipótesis de que el realismo artístico, haciéndose cargo de las vivencias epocales, fue un canal legitimante de la admisión de ciertos elementos cuestionables en la larga tradición artística de lo bello e incluso de la misma concepción teórica de los académicos. Lo deforme, lo feo, lo grotesco que se adscribía en forma simbólica al mal, al demonio, es decir, a agentes morales reales (en la concepción epocal el demonio no sólo es un ser real, sino que además obra realmente en el mundo de los humanos) se extiende al realismo de situaciones en que el mal es de otro tipo, no exclusivamente moral y no necesariamente demoníaco. De este modo se comienza a dar al arte un rol de exhibición y denuncia de los males reales de la humanidad, de forma inmediata, intuitiva, no argumentativa y por ende, de mayor alcance y difusión cultural: mueve a un sentimiento de piedad hacia las víctimas, y de responsabilidad personal y grupal, de autoridades y de gentes comunes.

La peste y la medicina. En lo relativo al tratamiento científico, es sabido que durante las dos epidemias de peste negra del siglo XIV en Europa, hubo al menos dos líneas de acción propiciadas por sendos grupos académicos y médicos ${ }^{3}$. El primero y más importante fue el de

\footnotetext{
${ }^{2}$ Este aspecto ha sido ampliamente analizado desde la perspectiva de la historia social de la ciencia. De los numerosos trabajos, cito en especial a ARRIZABALAGA, Jon, "La Peste Negra de 1348: los orígenes de la construcción como enfermedad de una calamidad social", Dynamis, Acta Hispanica ad Medicinae Scientiammque Historiam Illustrandam. 11, 1991, pp. $73-117$ (disponible en Internet). Plantea la visión de la sociedad contemporánea, que se componía de los dos ejes mencionados: la idea del castigo divino, y las concepciones sobre la pestilencia.

${ }^{3}$ Cf. ARRIZABALAGA, art. cit., quien analiza detenidamente seis de las obras médicas más significativas escritas sobre la peste en las fechas de la epidemia, cuyos autores fueron: Jacme d'Agramont, Gentile da Foligno, Giovanni
} 
la Sorbona que no sólo prevaleció en París, sino en general, en la mayoría de las ciudades de Europa Latina más golpeadas por la peste. El otro grupo, minoritario, estuvo conformado por médicos críticos de la tradición parisina, tanto en sus métodos de diagnóstico como en la terapéutica ${ }^{4}$. En líneas generales, significó el enfrentamiento entre la tradición médica que seguía aferrada a ciertos dogmas (por ejemplo los horóscopos médicos, los “días críticos”, etc.) y una tradición más nueva, en cierto modo surgida de la lectura más creativa del Canon de Avicena y otras obras árabes admiradas por ciertos pensadores también de avanzada 5 .

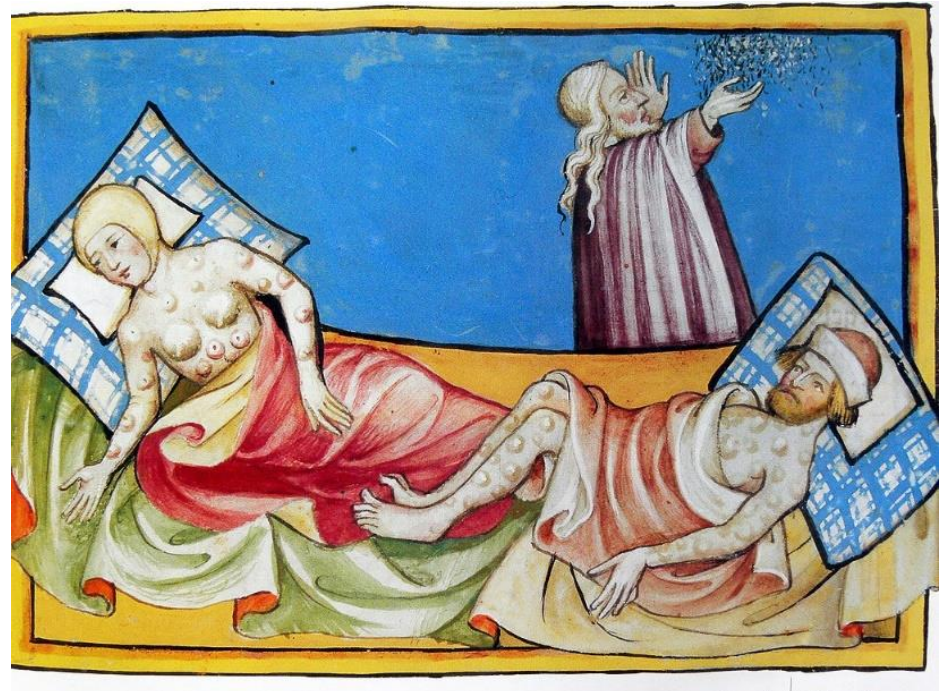

Biblia de Toggenburg - 1411

da Penna, Alfonso de Córdoba, un anónimo (práctico de Mo1ntpelller) y el Colegio de doctores de la facultad de medicina de París. Se detiene en mostrar cómo se fue construyendo el concepto de "pestilencia" (que abarca lo biológico y lo social) tanto por comparación con pestes anteriores de otro tipo, como enfocándose en exclusiva al caso bubónico. Al mismo tiempo señala la diferencia entre las tradiciones médicas en relación a lo religioso: mientras que algunos, incluyendo los médicos de París, se remiten a Dios en sus explicaciones médicas, los cercanos al de Montpellier se limitan a una invocación a Dios como fórmula ritual al comienzo y fin de sus escritos, pero sin involucrar ese aspecto religioso en sus explicaciones médicas o en sus propuestas terapéuticas.

${ }^{4}$ En todo caso, y conforme al art. cit., de Arrizabalzaga, el concepto de "infección" está presente en todos los escritos conocidos de la época y por tanto, aparece allí un justificativo científico de las medidas previsionales de aislamiento- Aun cuando los autores de los trabajos analizados (algunos médicos académicos y otros solo prácticos) disienten en muchos aspectos, hay un consenso en ciertos puntos fundamentales, lo cual le permite al autor concluir que "todo hace pensar que a mediados del siglo XIV los habitantes de las ciudades mediterráneas latinas estuvieron, en esta cuestión, profundamente influenciados por los saberes y las prácticas de la medicina universitaria" (p. 116).

${ }^{5}$ La Escuela de Medicina de Salerno fue una de las más activas, puesto que justo allí comenzó la peste y en consecuencia, la adopción de las primeras medidas sanitarias. Un dossier de amplios y complejos estudios históricos sobre este centro, en Practical medicine from Salerno to the Black Death, Edited by GARCÍABALLESTER, Luis, et alii, Consejo Superior de Investigaciones Científicas, Barcelona and Wellcome Unit for the History of Medicine Cambridge University, Cambridge University Press 1994. Destaco especialmente dos aportes que sirven de marco histórico a lo que aquí expreso: JACQUART, Danielle, "Medical practice in Paris in the first half of the fourteenth century" (p. 186-210) y GARCIA-BALLESTER, Luis, "A marginal learned medical world: Jewish, Muslim and Christian medical practitioners, and the use of Arabic medical sources in late medieval Spain” (p. 353-394). 
Esta imagen ${ }^{6}$ representa dos enfermos de peste, pudiéndose observar los numerosos bubones, como también reportan los documentos, siendo estos el síntoma más definitivo de la presencia del mal y de la casi inevitable muerte consiguiente. La cuestión de si y cómo tratar las bubas fue muy discutida entre los médicos. Sin embargo, al parecer hay pocos registros plásticos del tratamiento de punción (el más aceptado, al menos para ciertos casos), siendo éste uno que interesa, en mi concepto, porque representa lo que el imaginario colectivo inmediatamente posterior (la obra es de principios del siglo XV) asocia a la enfermedad y a la epidemia.

Por lo que hasta ahora se sabe a través de documentos fidedignos, en general el acatamiento a las ideas tradicionales, aun cuando no diera los resultados esperados, no alcanzó a ser cuestionado a fondo. Los investigadores se preguntan por qué. Es difícil establecer hipótesis, pero creo que una de las razones, no la única y quizá no la más importante, pero sin duda relevante, es su confluencia con el imaginario religioso epocal.

Desde el punto de vista religioso, además de las plegarias específicas, que no es el caso analizar aquí, hay que señalar lo que considero una revitalización de la antigua visión de los males (la enfermedad y, en este caso, la peste) como castigo de Dios por los pecados personales, o del pueblo en general ${ }^{7}$. Esta idea, de larga tradición judía, y que dentro de la Biblia canónica cristiana está incluida como texto revelado (el Libro de Job) produjo una considerable hermenéutica, así como el famoso paso evangélico en que se le pregunta a Jesús, “¿quién pecó, él o sus padres?" ante el caso de un ciego de nacimiento (Jn 9, 1.2). La idea de que la peste fue un castigo caló hondo en las conciencias, pero no necesariamente produjo en todos (quizá ni siquiera en la mayoría) un espíritu de contrición y enmienda. Al contrario, el libertinaje también fue un escape, como lo muestra claramente el Decamerón. Pero el poder religioso, en concordancia con las autoridades civiles, apoyaba esta idea para lograr mayor obediencia a las medidas de prevención que se tomaban (más o menos las mismas que ahora: aislamiento, separación de los enfermos, entierros sin rituales y con medidas asépticas que resultaban lesivas a los sentimientos de los deudos).

\footnotetext{
${ }^{6}$ Ilustración de la Peste en la Biblia de Toggenburg (1411) representando a dos apestados con gran número de bubones. Precisamente esta imagen pone en cuestión cuál fue el virus que ocasionó la peste. Un estudio muy reciente, secuenciando el ADN de restos humanos de la época, concluye que pudo ser Yersina pestis, pero este virus no produce bubones (dato tomado de Wikipedia).

${ }^{7}$ En relación con esta epidemia y las reacciones de los prácticos y de la gente común. ver ARRiZABALAGA, Jon, "Facing the Black Death: perceptions and reactions of university medical practitioners", en Practical medicine from Salerno to the Black Death cit., p. 237-288.
} 
La idea también evangélica "dejad que los muertos entierren a los muertos" (Mt 8, 22) que por supuesto está dicha en otro contexto y con otro sentido, campea, me parece, en el imaginario artístico de los artistas de los siglos XV y XVI, que habían vivido poco después de la peste y conocían sus secuelas.

Esta idea del castigo del pecado y de poner a los muertos a cuidar a los muertos tiene dos representaciones plásticas reiteradas en la época: las "danzas de la muerte" y las representaciones de entierros. Vinculo esas imágenes a esta idea que acabo de enunciar porque me parece que les cuadra perfectamente.

Tomo dos ejemplos de "danzas de la muerte"

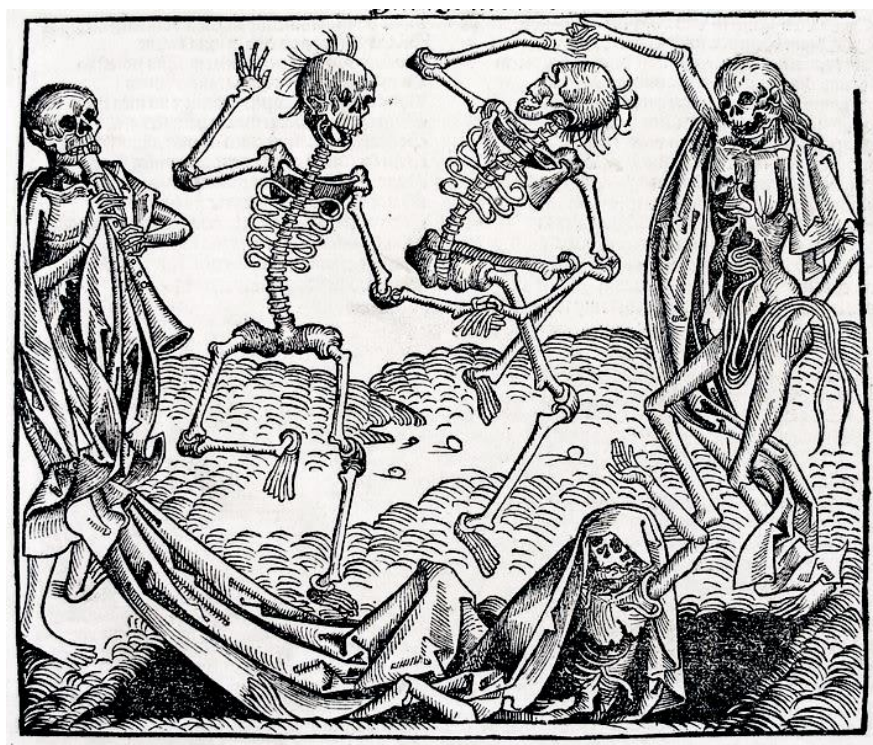

Michael Wolgemut (1434-1519) - Danza de la Muerte (1493) - Nüremberg

En: Hartman Schedel - Crónicas de Nüremberg (1493)

Foto: https://es.wahooart.com

Esta obra $^{8}$ fue mal atribuida a Hans Holbein, pero luego de cuidadosos estudios se comprobó que no era de su autoría sino de Wolgemut. En ella se representa una danza macabra que no se refiere en sí a la peste, pero que pudo tener inspiración en ella. Se observa un esqueleto tocando la trompeta (alusión quizá a las siete trompeta de Apocalipsis 8, 2 ss.) que despierta a

\footnotetext{
${ }^{8}$ Imagen y nota histórica tomada de CODESEIRA DEL CASTILLO, Celia, "Representaciones plásticas de la muerte durante las epidemias de peste que afectaron Europa entre los siglos XIII y XVII", en LÉRTORA MENDOZA, Celina Ana, Manuel Belgrano y la ciencia Argentina. XX Jornadas de Historia del pensamiento científico argentino. Actas, Buenos Aires: Ed. FEPAI, 2020, p. 133-158. Este artista fue pintor y grabador alemán de la última fase del gótico, llamado "estilo flamenco", y trabajó siempre en Nüremberg. En su taller tuvo una legión de discípulos entre los que sobresalió el luego famoso Albert Durero. Ilustró el libro Crónicas de Nüremberg junto al alemán Wilhelm Pleydenwurff, editado en 1493. La obra fue publicada en dos versiones: una latina y otra alemana, lo que permitió su difusión por toda Europa. En ella se narra la historia universal basándose en el relato de la Biblia. Se destaca por los numerosos grabados y por contener el primer mapa impreso de Alemania. Tomo esta imagen de este artículo, p. 139.
} 
los otros esqueletos que bailan y juegan, incluso el de la derecha, lo hace con sus intestinos, lo que sin duda es una representación no sólo grotesca sino también bastante asquerosa.

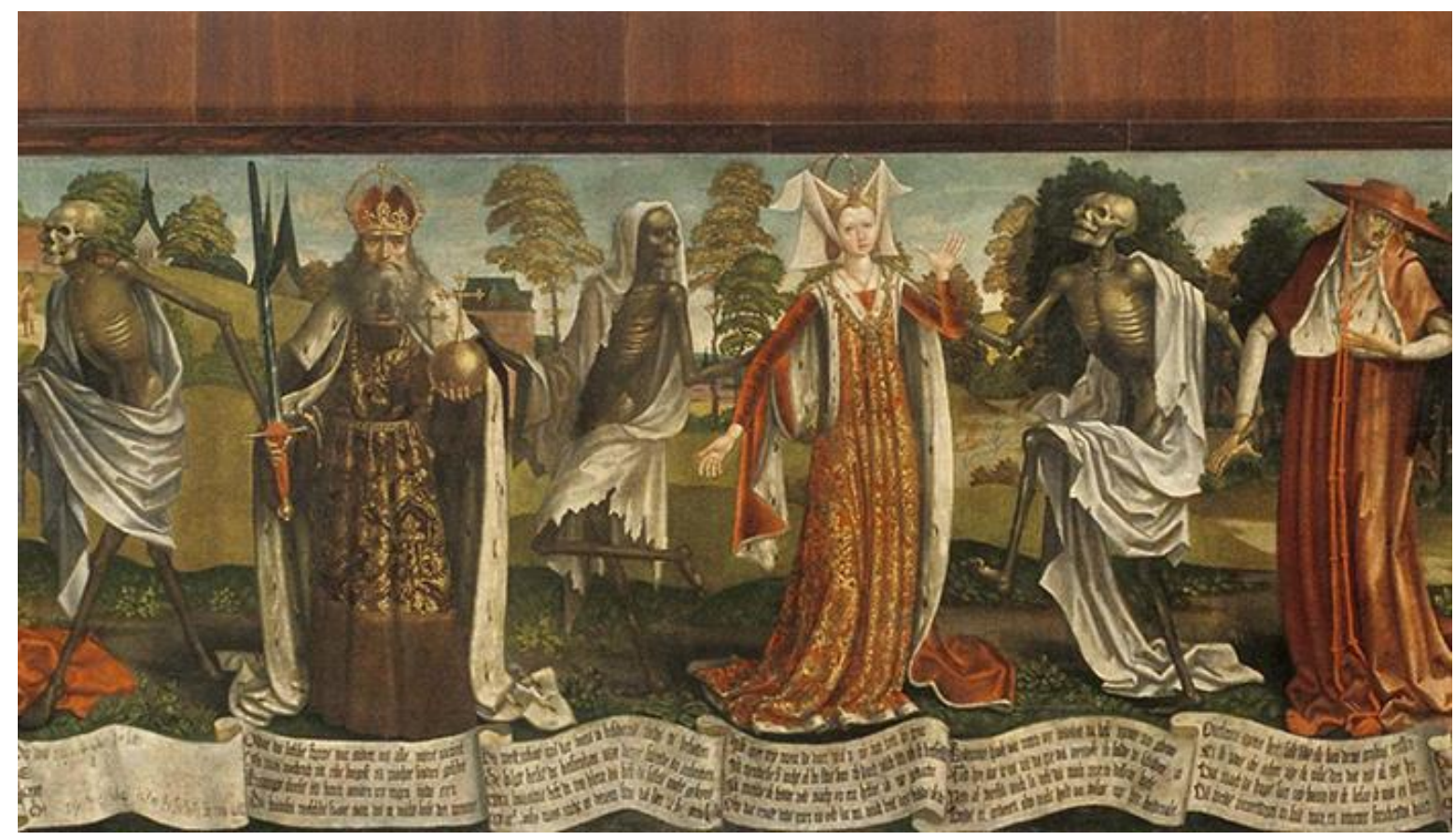

Bernt Noltke (1440-1509) - Danza macabra -óleo sobre tela - fragmento Museo de Arte Sacro de la Iglesia de San Nicolás -Tallin (Estonia)

Foto: www.misterica.net

La segunda imagen es una danza macabra de Noltke ${ }^{9}$, también contemporáneo de las graves secuelas de la peste. En el cuadro aparece el rey con sus atributos que son la espada y el orbe de los reyes santos; la reina luce su corona y hay otros dignatarios. Cada figura humana está tomada por las manos de los esqueletos, es decir, aparecen enlazados alternadamente una persona y su propia muerte, por toda la obra. Como puede apreciarse, esta pintura mixtura el realismo con lo ficcional, la "danza" en su aspecto grotesco, está a cargo de los esqueletos que representan la muerte, mientras que los personajes aparecen dignos, mientras juegan con su propia muerte futura. Esta obra es claramente reflexiva, pone en consideración la necesidad de tomar en cuenta que somos "seres para la muerte", como diría Heidegeger siglos después. Y lo hace mezclando la concepción del arte bello con el grotesco, en un mix en el que, al menos para nuestro gusto actual prevalece lo estético armonioso, pues los mismos esqueletos están en parte

\footnotetext{
${ }^{9}$ Tomo la imagen y nota de CODESEIRA DEL CASTILLO, art. cit., p. 140. La "Danza de Lübeck" fue pintada, en el siglo XV, en Alemania por Bernt Notke (1440-1509). Luego esa imagen fue traslada a la Iglesia de Santa María en 1710. Durante la Segunda Guerra Mundial un bombardeo del ejército aliado la destruyó, pero se conservan fotografías. Asimismo, se encontraron algunas partes del original, que medía 30 metros de largo.
} 
vestidos con especies de túnicas de color y pliegues bien trazados, no tienen ese aspecto un tanto repugnante del conjunto que se aprecia en la imagen anterior.

En ambos casos las imágenes tienen un claro contenido religioso, aunque los símbolos religiosos epocales no están explícitos. Los plásticos de finales del XV, a un siglo de la peste, sin duda la visualizan como el caso más claro del "gran triunfo de la muerte" por la rapidez y la cantidad de víctimas, siendo muy superiores a las de otros desastres, como los incendios o los naufragios, mucho más acotados.

El otro tema vinculado a la muerte y sobre todo a la mortandad es el de los entierros. Aquí debemos señalar varios aspectos que vinculan el entierro h el arte- Por una parte, hay una larga e importante tradición artística de los enterramientos, desde los primeros tiempos del neolítico. Los grandes personajes, pero también los humiles, en la medida de sus posibilidades, querían tener una tumba digna y adecuada a lo que habían sido en vida, para albergar sus restos. La idea del juicio del más allá (que aparecen en Egipto por lo menos 2500 años antes de nuestra era) fue sin duda un detonante para el avance artístico representativo de humanos y dioses. Las tumbas griegas y romanas, de gran valor artístico, son otro ejemplo importante de este sentimiento. En la Edad Media, es decir, en la época de la peste que nos ocupa, esta tradición de los sarcófagos artísticos se había mantenido e incluso había crecido, hasta el punto de que todas las iglesias de cierta importancia albergaban tumbas artísticamente dispuestas, según los criterios estéticos de cada época., siendo el gótico el modelo en el siglo XIV. Pero labrar un sarcófago requería tiempo y dinero, así como disponibilidad de artesanos, cosa que durante la peste e incluso después, se hizo problemática. La mayoría de los muertos, incluso nobles, debían ser enterrados en fosas comunes cubiertas de cal para evitar la pestilencia (es decir, los focos de contagio). Los grandes ceremoniales fúnebres quedaron reducidos a unas pocas oraciones, a veces para muchos muertos a la vez, pronunciadas por los pocos religiosos disponibles. Esa idea del abandono del muerto, de la falta de esa última despedida (que hoy también añora en situación de cuarentena), la despedida definitiva al mundo pero también su pasaje al más allá (para la gloria o la condenación, ambas posibilidades igualmente tremendas aunque de signo contrario) debió quedar muy fijada en el imaginario social, aun cuando los testimonios plásticos que tenemos no sean abrumadores.

Presento dos imágenes de enterramientos que a mi juicio representan lo aspectos que acabo de mencionar. 


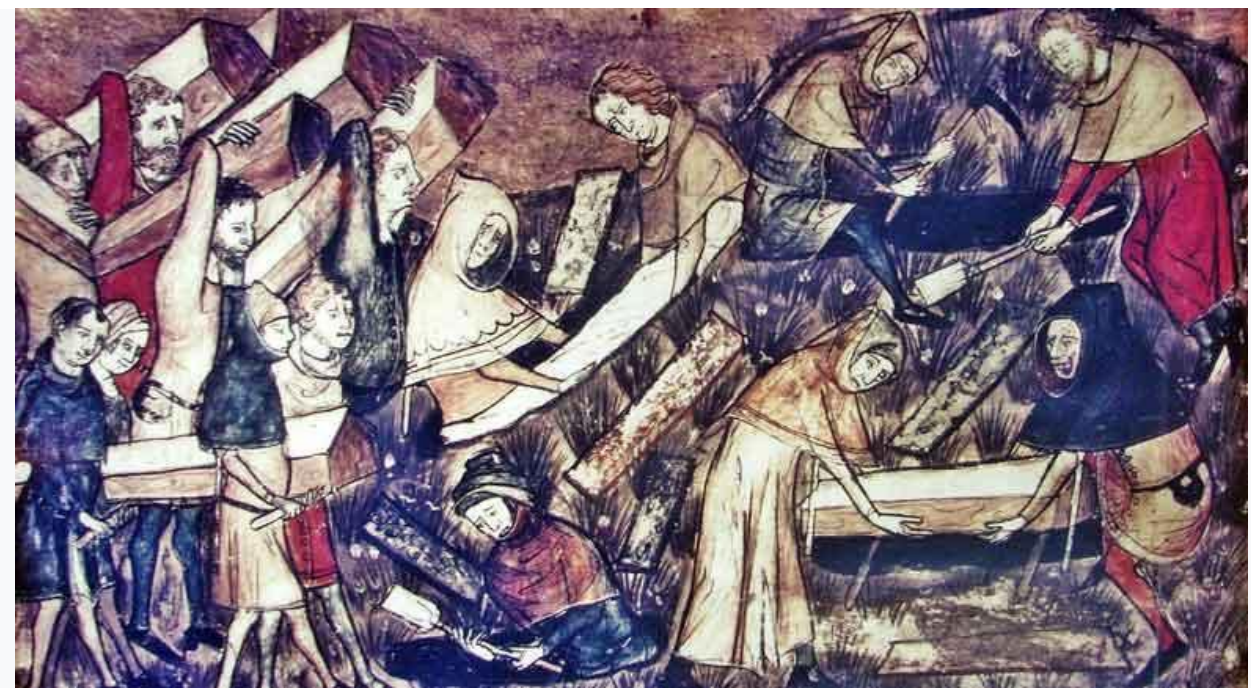

Anónimo - Pobladores de Tournai entierran a sus víctimas de la peste negra de 1349 siglo XIV Miniatura de las Crónicas de Gilles Le Muiset ${ }^{10}$

Biblioteca Real de Bélgica

Esta miniatura representa claramente los enterramientos desordenados, sin ritual, sin ceremonial, sin pompa y con mucha angustia, todo debía hacerse con rapidez y revelaba mucho temor La muerte perdía la dignidad de los grandes ceremoniales y adquiría un matiz sombrío y desagradable. Este imaginario terminó prevaleciendo en los siglos siguientes.

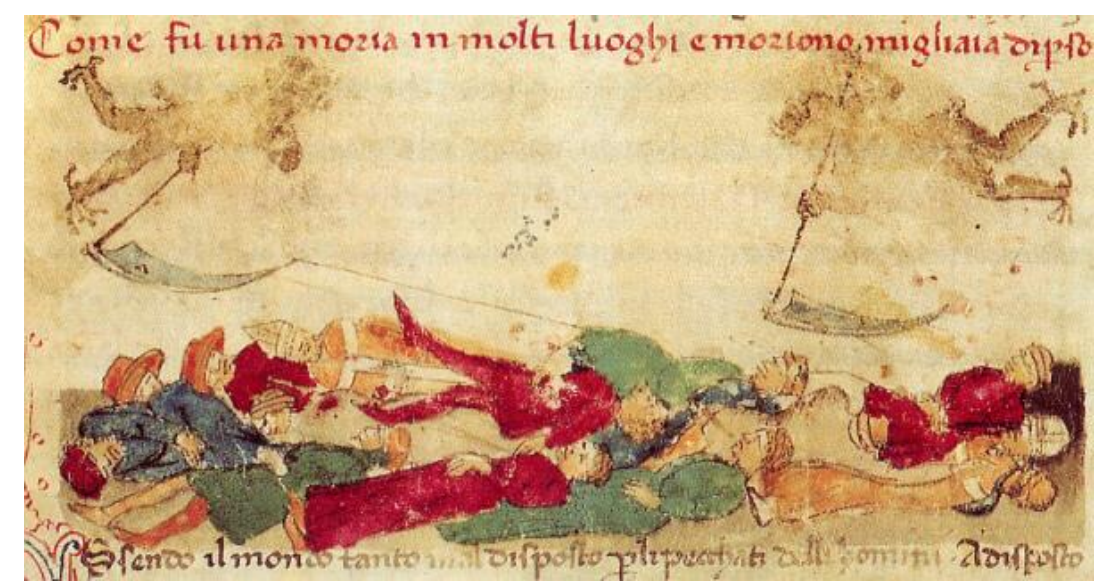

La peste negra - miniatura - Lucca - siglo XIV

Crónica de Giovanni Sercambi - Archivo del Estado de Lucca (Italia)

\footnotetext{
${ }^{10}$ La miniatura muestra una escena cotidiana realizada por los habitantes de Tournai, Bélgica, durante la peste negra y representa lo que el artista anónimo habría observado personalmente. El autor de las Crónicas, Gilles Le Muiset ó Gilles Li Muisis (1272-1352), fue un poeta y cronista nacido en Tournai. Por su vocación religiosa, en 1289 ingresó al Convento Benedictino de la Abadía de San-Martin en su ciudad natal. Llegó a ser prior y abad. Cf. CODESEIRA DEL CASTILLO, art. cit., p. 143, imagen y nota histórica.
} 
Esta imagen ${ }^{11}$ muestra también, más que un enterramiento, el hacinamiento de los cadáveres, todavía vestidos, arrojados en las calles o en cualquier sitio, por falta de de enterradores suficientes.

\section{LA VIRUELA DE LOS SIGLOS XVI-XVII-XVIII}

La viruela fue una de las pestes más recurrentes en Europa y América en estos siglos, pudiendo mencionarse también el sarampión, la escarlatina, la difteria, el tifus, el cólera, la fiebre amarilla, la tuberculosis, entre las más conocidas ${ }^{12}$. La mortandad ocasionada por estas epidemias fue enorme, tanto en Europa como en América donde, especialmente en México, la población nativa quedó enormemente reducida. Estos hechos, muy conocidos por haber sido narrados repetidamente por testigos, también ha permitido considerar la existencia de enfermedades infecciosas epidémicas anteriores y posteriores a la llegada de los españoles ${ }^{13}$. Es decir que, a las plagas ya presentes en la época prehispánica, se sumaron las traídas por los conquistadores y luego, especialmente a partir del siglo XVII, las que llegaban de África con los negros esclavos. Hay abundantes testimonios y descripciones literarias y plásticas de estas enfermedades, cuya consideración excede el marco de este trabajo ${ }^{14}$.

Aquí me voy a referir solamente a la viruela, que es emblemática por las imágenes detalladas de los efectos en el aspecto físico (en esto se asemeja a la lepra, aunque es menos impactante) sobre todo en el rostro. Pero aquí una situación importante que la diferencia de otras dolencias:

\footnotetext{
${ }^{11}$ Cf. CODESEIRA DEL CASTILLO, art. cit., p. 148.

${ }^{12}$ Referencias a estas pestes y sus imágenes plásticas en TOPOLANSKY, R., ob. cit., cap. 8: “Las infecciones y otras enfermedades" donde muestra una curva considerable en el imaginario social desde la Edad Media al siglo XIX, en cuanto a la gravedad y temor de contagio, que va desde la lepra (continuando en épocas medievales la antigua tradición sobre todo en Medio Oriente, de aislamiento absoluto y rechazo social del leproso) hasta el cólera y la fiebre amarilla, que asoló varias ciudades de América del Sur, entre ellas Buenos Aires, c. 1870 ss.

${ }^{13} \mathrm{Al}$ parecer en América indígena, y sobre todo en la zona de México, las epidemias, de etiología en muchos casos desconocida por la vaguedad de las referencias documentales, estuvo bastante vinculada a las hambrunas recurrentes. Cf. VIESCA, Carlos, "Hambruna y epidemia en Anáhuac (1450-1454) en la época de Moctezuma Ilhuicamina", en FLORESCANO E. y M. Elsa (eds.), Ensayos sobre la historia de las epidemias en México, México, Instituto Mexicano del Seguro Social, 1982, p. 157-165. En este caso resulta aún más acentuada la idea de vincular los desastres a la divinidad (sumatoria de desgracias) lo que motivaba también a redoblar las plegarias y los sacrificios, incluso cruentos.

${ }^{14}$ Menciono solamente un trabajo que vincula la expansión de las pestes desde Europa a América como caso de incipiente "mundialización" del fenómeno, es decir, la aparición del concepto de "pandemia": CORDERO DEL CAMPILLO, M., "Las grandes epidemias en América Colonial”, Archivos de Zootecnia 50: 2001, pp. 597-612. Comparto la conclusión final del autor quien, luego de repasar algunas de las observaciones que, sobre estas epidemias, constan en las Cartas Annuas jesuitas, manifiesta: "La segunda enseñanza que se extrae del análisis de las epidemias es el potencial que tienen para afectar a las poblaciones afectadas ex novo, que puede llegar a la eliminación de grandes contingentes e influir en la decadencia de civilizaciones" (p. 611).
} 
fue la primera gran peste que tuvo vacuna tempranamente ${ }^{15}$ y que, además, hoy ha suido definitivamente erradicada. A diferencia del caso anterior, para el cual no hoy hay una terapia sólida y ni siquiera una prevención eficaz, la viruela puede ser presentada como una peste en que el triunfo de la ciencia es clarísimo y por tanto desde el siglo XVIII aparece la vacuna como un elemento salvador, esperanzador, que el arte se ocupa de señalar.

En este caso y a diferencia de los otros, hay imágenes en número significativo, mostrando el remedio adecuado. Tal como es sabido, la viruela es una enfermedad de las vacas y la vacuna se obtuvo en un principio del pus de animales infectados, que luego fue siendo reemplazado por sueros que producían menor reacción dolorosa o peligrosa, inmunizando sin embargo de la misma manera total ${ }^{16}$.

El arte que representa este logro científico aparece en la época del clasicismo y desde el punto de vista cultural es coetáneo a la Ilustración y al Iluminismo.

Pongo un solo ejemplo de una pintura que representa este cambio de actitud. En ella no se representa la enfermedad sino la prevención, no hay dramatismo sino serenidad y confianza. Se aprecia al niño sostenido por su madre, un tanto receloso, pero no muy asustado. Dos personas más observan con interés el procedimiento: una niña y un joven, tal vez ya inoculados o que van a serlo próximamente. En este caso la obra de arte trasmite un mensaje de confianza en el procedimiento concreto y en la ciencia en general. Debe observarse. además, el aspecto social. Las personas representadas no son ricos ni nobles, pero tampoco son desarrapados ni mendigos. Pertenecen claramente a la clase burguesa, la "clase media" que componía ya por entonces la parte más activa y productiva de la población. El interés se ha desplazado de los nobles y los miserables (los dos extremos) de las imágenes medievales, a otro sector social que, por otra parte, puede interiorizar claramente el mensaje del cuadro.

\footnotetext{
${ }^{15}$ El médico inglés Edward Jenner (1749-1823) fue el inventor de la vacuna antivariólica eficaz y todavía en uso, superando a otros médicos que desde 1760 trabajaban en la inoculación siguiendo prácticas al parecer mucho más antiguas y referidas a otras dolencias. Pero fue su sistema y su metodología lo que permitió el éxito del tratamiento. Escribió varias obras sobre este tema, la primera de las cuales es fundamental para la historia del procedimiento: An Inquiry intro the Causes and Effects of the Variolæ Vaccinæ (1798). Dentro de la inmensa bibliografía de difusión, puede verse VILLANUEVA-MEYER, Marco, "Edward Jenner (1749-1823): Pionero de las vacunaciones y la inmunología" (disponible en (https://www.galenusrevista.com/IMG/pdf/Edward_jenner.pdf).

${ }^{16}$ La relativa sencillez en la elaboración de la vacuna, así como la facilidad de su uso, permitieron una rápida expansión de este recurso, que llegó tempranamente también a América. Se sabe ahora que el neogranadino Antonio Nariño, el prócer de la Independencia de su virreinato, trabajaba en la confección de una vacuna antivariólica sobre la base de la conocida, para aplicar en su país; la documentación está siendo investigada por Fredy Moreno Gómez, profesor de una Universidad Javeriana de Cali (cf. http://www.javerianaestereo.com/antonio-narino-y-la-vacuna-contra-la-viruela/).

Por otra parte, en el virreinato del Río de la Plata fue tempranamente introducida gracias a las gestiones de Manuel Belgrano, también prócer de la independencia (Cf. BORES, Amalia y BORES, Inés, "Manuel Belgrano y su impronta en la sanidad", en LÉRTORA MENDOZA, Celina A., Manuel Belgrano y la ciencia argentina, cit., p. 18.24).
}

Sapere aude - Belo Horizonte, v. 11 - n. 22, p. 400-416, Jul./Dez. 2020 - ISSN: 2177-6342 


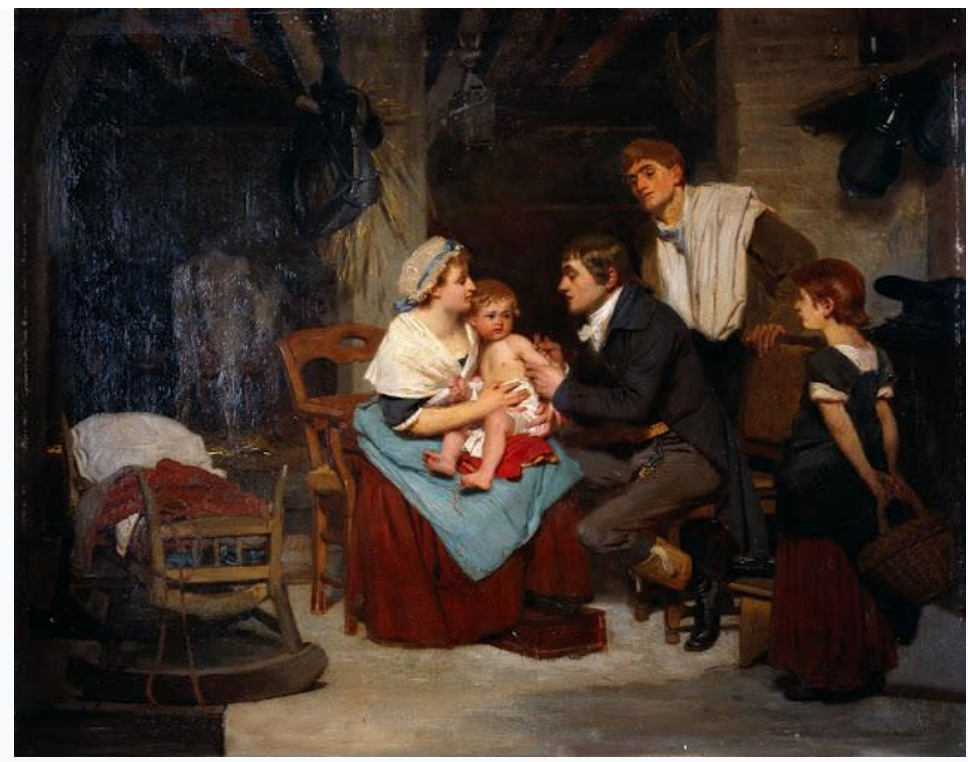

http://medicinaybellasartes.blogspot.com/2012/04/edward-jenner-vacunando-un-nino-contra.html

Otra imagen que presento, la considero posterior, aunque no tiene fecha, representa otro aspecto del arte que en el futuro tendrá considerable relevancia: la propaganda. A diferencia del cuadro, en que el mensaje es implícito, subliminar e indirecto, en esta imagen, que recuerda a un flyer actual, se aprecia un mensaje directo: a la izquierda la persona con los efectos del mal, a la derecha, la solución preventiva. El mensaje es evidente: vacúnese para evitar el contagio. Pero por otra parte, la imagen es discreta, el individuo afectado no aparece deteriorado, se lo ve joven y sano (bien nutrido, sin otros defectos visibles). O sea, que el mensaje está dirigido a personas más o menos semejantes. Y el aspecto docente de la imagen de la vacunación es también tranquilizador: no se trata de nada doloroso, dramático, como los fierros candentes, o las incisiones profundas que producen mucho sangrado; se aprecia que se trata solamente de una mínima punción. Esta nota tranquilizadora del tratamiento de vacunación es un aspecto tempranamente tenido en cuenta y que hoy, como se verá en el punto siguiente, está en plena discusión.

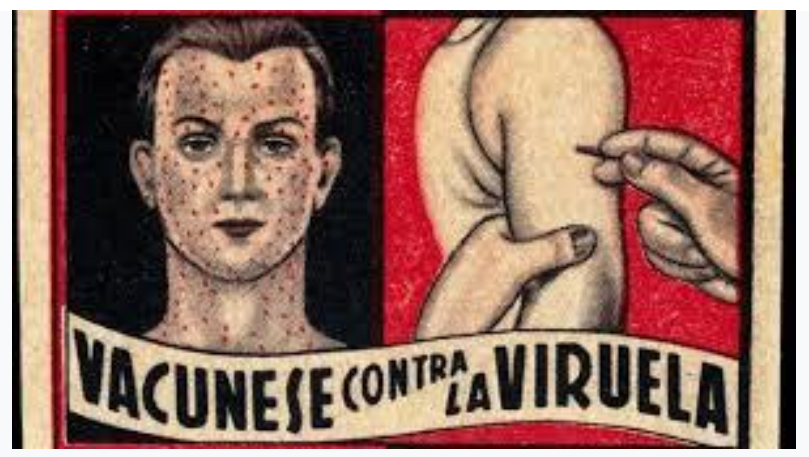

Wikipedia 


\section{EL CORONAVIRUS DEL SIGLO XXI}

El Covid-19 es una pandemia diferente a las dos mencionadas y a todas las anteriores, diríamos que es inconmensurable con ellas. Porque mientras todas las otras, aun siendo muy extendidas, siempre fueron localizadas, y sus curvas de reinfección tenían que ver con nuevas situaciones, no eran reinfección del mismo virus por los mismos habitantes de los lugares infectados.

El Covid-19 es la primera pandemia absoluta, abarca todo el mundo, prácticamente ningún país ha quedado libre de infectados y muertos. En un mundo super-conectado y globalizado, la infección se extendió en forma incontrolable y obligó a medidas de aislamiento totalmente inéditas. Durante meses casi todo el mundo estuvo en cuarentena, con actividades restringidas y con un conteo de infectados y fallecidos a nivel mundial. La tecnología que ha servido para dar a conocer en tiempo real el avance y la gravedad del cuadro, no ha servido todavía para dar con ninguna solución claramente eficaz. Casi todos los países han puesto sus sistemas científicos y sus laboratorios al servicio de nuevas y mejores formas de testear los infectados, de tratar a los enfermos y de impedir contagios. Los resultados han sido bastante relativos y han producido un gran desencanto, cuando no una considerable desconfianza y escepticismo en grandes sectores de la población mundial.

Ninguna otra peste en el siglo XX y en las dos primeras décadas del XXI ha tenido una cobertura periodística no digamos igual, sino ni siquiera comparable; nunca los equipos de epidemiólogos han tenido tanta relevancia, incluso política. Se ha llegado a hablar de una "infectadura" (dictadura de los infectólogos) lo que sin duda es un exceso, pero marca una tendencia de descreimiento y negacionismo ante la ciencia, incluida la vacuna, a la inversa de la confianza social del siglo XVIII. Más aún, la existencia de varias vacunas de diferente tipo, en fase de prueba $\mathrm{p}$ de primera aplicación voluntaria, pero cuya composición resulta una incógnita, ha derivado en una notable suspicacia sobre el verdadero objetivo de los gobiernos que quieran reglamentarla con obligatoriedad.

Se ha escrito mucho, numerosos libros, artículos periodísticos, tanto por médicos especialistas, como por literatos, analistas, sociólogos, politólogos, historiadores, filósofos. Es un material ingente que necesita ser analizado y evaluado, algo que no está en mi posibilidad. Solamente quiero significar que este tercer momento de relación con el arte es muy diferente a los anteriores y marca también los contrastes sociales, políticos, económicos y médicos que atraviesan desordenadamente el imaginario social produciendo una impresión caótica. 
No encontré productos artísticos representativos de esta pandemia del mismo tipo que los anteriores. La plástica requiere un tiempo de producción que no se ha dado, y también quizá porque ha sido reemplazada, más rápidamente, por la fotografía y el vídeo. Innumerables imágenes de las ciudades desiertas, la impactante Venecia con los canales de agua azul transparente y las gaviotas blancas son quizá uno de los modelos que el arte, en este caso, la fotografía, nos ofrecen como alerta pedagógico sobre los beneficios de las cuarentenas, pero también el imprevisible giro negativo de una economía paralizada, como lo muestran numerosos fotografías de las calles desiertas de las grandes ciudades y los negocios, fábricas y empresas con las persianas bajas. Las imágenes de los médicos, enfermeros y salas de terapia, que acompañan a los cómputos de infectados y muertos, pero también de recuperados, constituyen el tercer eje de información y de mensaje subliminar, así como las fotografías y vídeos de funcionarios, políticos, legisladores, magistrados, artistas, periodistas, profesores y otros agentes que deben exponerse al público, con mascarillas (o sin ellas, lo que produce gran reprobación social). Finalmente el teletrabajo, y las imágenes de sesiones parlamentarias, reuniones de gabinete de ministros, juicios online, es también una ilustración inédita por su cantidad y calidad de mensajes ambiguos y de repercusiones variadas, que van desde la indignación a la absoluta indiferencia. Estamos transitando un momento inédito en la historia de la cultura humana que podamos recordar.

Pese a esta carencia de imágenes plásticas adecuadas en cuanto reproductivas y realistas, me permito ofrecer dos composiciones fotográficas. realizadas por una artista argentina, Catalina Pantuso, con imágenes trabajadas en computadora ${ }^{17}$. No son descriptivas, y ya tenemos imágenes en exceso, como acabo de indicar. Son composiciones más bien abstractas cuyo significado debe ser desentrañado, pero cuya interpretación no es demasiado complicada.

La primera imagen, titulada Covid-19 es, como puede apreciarse, una interpretación libre de los modelos científicos del virus, que representa su expansión en un lenguaje fractal. En realidad se trata de una secuencia de diversas imágenes de composición (que aquí no se presentan) La primera es tomar un estropajo metálico de cocina como imagen del virus, que en esta composición se aprecia hacia la derecha arriba y que produce una onda expansiva con centro claro y límites imprecisos. Es una imagen que evoca adecuadamente la misma imprecisión científica acerca del virus, su procedencia, su etiología, su ciclo y sus posibles mutaciones.

\footnotetext{
${ }^{17}$ Se trata de una serie, parte de la cual está subida en la página de Fundarte 2000, (www.fundarte2000.fepai.org.ar) en una galería de trabajos artísticos dedicados a la pandemia_ "la peste y el arte".
} 


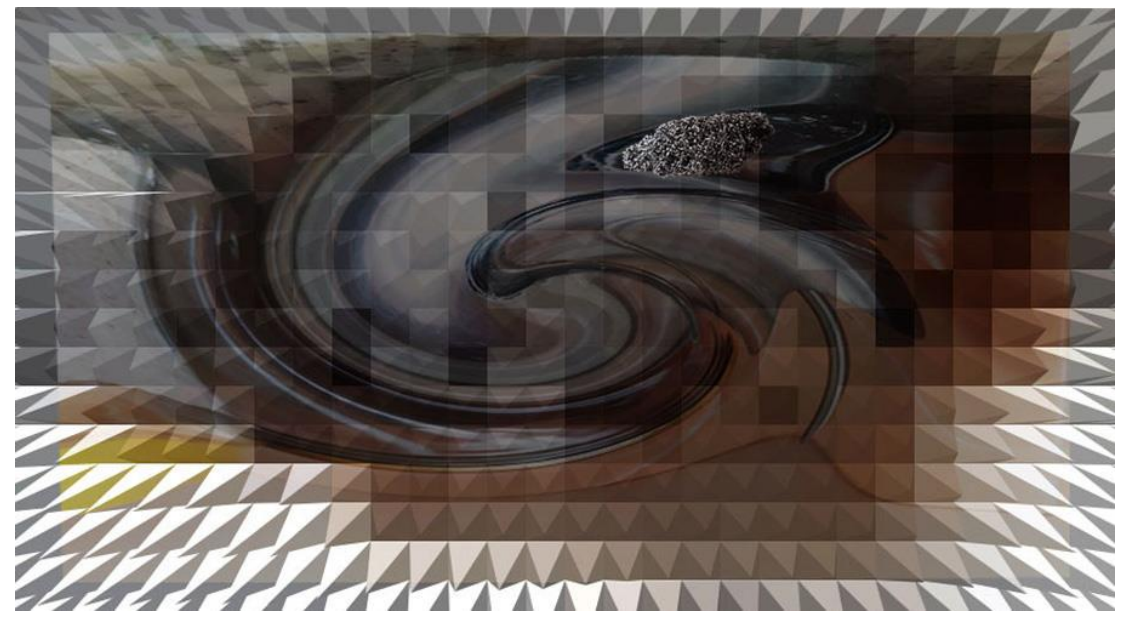

Catalina Pantuso - Covid-19

La segunda imagen es también de una serie titulada "Improvisación científica", que me parece una ironía a su propia composición y al mismo tiempo una ironía sobre el tratamiento "científico" de la pandemia. Sobre un fondo arremolinado (expresión de cierto caos), una rosa de los vientos, es decir, la representación de todo el mundo, todos los lugares, cubierta parcialmente por elementos fragmentarios, rotos, incompletos. Constituye un mensaje más bien escéptico sobre el enfrentamiento a la pandemia.

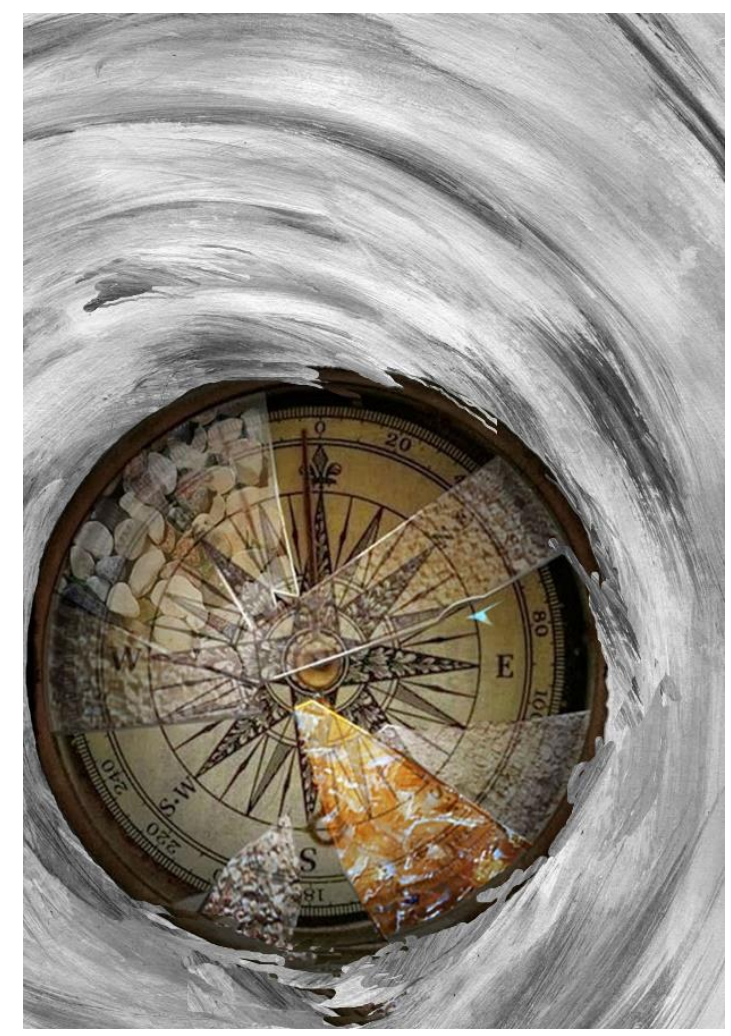

Catalina Pantuso - Improvisación científica 2 


\section{ALGUNAS REFLEXIONES}

He intentado cruzar ideas médicas con representaciones plásticas de tres momentos de peste (la peste negra del siglo XIV, las de viruela sobre todo en el siglo XVIII y el Covid-19) para mostrar cómo el arte se apropió y representó el imaginario colectivo de cada época acerca de esas tragedias. Me propongo ahora reflexionar en ese rol artístico en parte cambiante y en parte sostenido a lo largo de todos estos siglos.

Aprecio que, en primer lugar, el arte ha funcionado como un disparador catártico. Tal como ya lo decía Aristóteles, la representación del destino trágico del héroe en la escena, es decir, distanciado del sujeto que contempla la representación, produce un sentimiento de empatía provocando por cierta identificación, la catarsis sobre su propia realidad. El rol catártico del arte, en general, pero en especial del arte representativo o temático, ha sido muy señalado y no es necesario abundar en ese aspecto que, por lo demás, es más que claro en los tres casos que he analizado.

Pero sobre todo me interesa destacar otro aspecto, que no ha sido en general muy considerado por los estetas, y que en parte se deriva del efecto catártico, aunque es distinto de él: la propuesta implícita del "cuidado de sí", al plasmar los graves efectos de estas desgracias colectivas. En efecto, esta línea filosófica actualmente en crecimiento, considera que el cuidado de si (epiméleia heautoû, cura sui) constituye una tradición teórica que se remonta hasta Sócrates, tal como Platón lo expresa en Alcibíades I. Aunque sin darle exactamente ese nombre, tal línea teórica ha transitado las diversas épocas y enfoques, adaptándose a -y expresándose según- diversas tradiciones filosóficas. En el siglo han trabajado este tema, con sus propias variantes, pensadores en otros aspectos muy diferentes, como Martin Heidegger, Pierre Hadot, Michel Foucault y Peter Sloterdijk entre otros. Podría decirse que su rasgo común es considerar que la filosofía no es sólo un saber fundado (episteme) sino también una sabiduría (sophia) que busca un modelo de vida, un modo "sabio" de vivir y por lo tanto un "arte de la existencia". Una existencia en que el bien y el mal, la felicidad y la desgracia, el éxito y el fracaso están siempre presentes, misturándose en diversas proporciones pero en todo caso formando realidades complejas y cambiantes a las que el hombre como individuo y como grupo y hasta como especie debe hacer frente. Esta búsqueda reclama una mirada interdisciplinar (ética, política, religiosa, médica, etc.) que atañe a todas las disciplinas humanísticas y a todo el campo de la cultura. Es aquí donde el arte, haciéndose cargo por una parte del imaginario social y por otra de la realidad que enfrenta la medicina, nos da una prueba de que esa catarsis ya sugerida 
(y propiciada) por Aristóteles, adquiere toda su dimensión sapiencial y salvífica. El arte nos pone frente a la realidad, nos muestra su lado más oscuro, pero también nos proporciona un apoyo anímico para superarla inmovilidad del temor y la desesperanza.

Finalmente, quiero señalar que tanto el rol catártico como la cuestión del cuidado de sí a través de la dimensión pedagógica, motivadora y exhortante a la vez, propició y/o fortaleció cambios en la concepción misma de la obra artística. En los dos primeros casos. Resta por saber si la pandemia actual producirá similares o distintas derivas.

\section{BIBLIOGRAFIA}

ARRIZABALAGA, Jon. "Facing the Black Death: perceptions and reactions of university medical practitioners". In: Practical medicine from Salerno to the Black Death. p. 237288.

ARRIZABALAGA, Jon. "La Peste Negra de 1348: los orígenes de la construcción como enfermedad de una calamidad social”, Dynamis, Acta Hispanica ad Medicinae Scientiammque Historiam Illustrandam. 11, 1991, pp. 73-117.

BORES, Amalia; BORES, Inés. "Manuel Belgrano y su impronta en la sanidad". In: LÉRTORA MENDOZA, Celina A. Manuel Belgrano y la ciencia argentina. XX Jornadas de Historia del pensamiento científico argentino. Actas, Buenos Aires: Ed. FEPAI, 2020, p. $18-24$.

CODESEIRA DEL CASTILLO, Celia, "Representaciones plásticas de la muerte durante las epidemias de peste que afectaron Europa entre los siglos XIII y XVII". In: LÉRTORA MENDOZA, Celina Ana. Manuel Belgrano y la ciencia argentina. XX Jornadas de Historia del pensamiento científico argentino. Actas, Buenos Aires: Ed. FEPAI, 2020, p. 133-158.

CORDERO DEL CAMPILLO, M. "Las grandes epidemias en América Colonial". Archivos de Zootecnia 50: 2001, pp. 597-612.

GARCÍA-BALLESTER, Luis, et alii. Consejo Superior de Investigaciones Científicas. Barcelona and Wellcome Unit for the History of Medicine Cambridge University, Cambridge University Press 1994.

TOPOLANSKY, Ricardo. El arte y la medicina. Montevideo, 2004-2005, Introducción. VIESCA, Carlos, "Hambruna y epidemia en Anáhuac (1450-1454) en la época de Moctezuma Ilhuicamina". In: FLORESCANO E.; M. Elsa (eds.). Ensayos sobre la historia de las epidemias en México. México, Instituto Mexicano del Seguro Social, 1982, p. 157-165.

VILLANUEVA-MEYER, Marco, "Edward Jenner (1749-1823): Pionero de las vacunaciones y la inmunología" (disponible en (https://www.galenusrevista.com/IMG/pdf/Edward_jenner.pdf). 